\title{
THE CONTENT OF ORGANOCHLORINE PESTICIDES AND THEIR DERIVATIVES IN THE SOIL NEAR THE AREAS OF AGROCHEMICALS
}

\author{
Department of Animal Science and Fodder Production, Lviv National Agrarian University, Ukraine \\ ${ }^{1}$ Institute of Agriculture of Carpathian Region, Ukraine \\ ${ }^{2}$ Department of Biology, Rivne State Humanitarian University, Ukraine
}

\begin{abstract}
They conducted an ecotoxicological survey of the soils of the sanitary zones of nonactive agrochemical warehouses and established the boundaries of chlorinated organic pesticide-polluted zones. Studies on dark grey, podzolized soils in the conditions of the Western Forest-Steppe of Ukraine found that there is a spatial migration of organochlorine pesticides and the degree of chemical degradation of soils is estimated.
\end{abstract}

Key word: chlororganic pesticides, dark-grey podzolized soils, pollution soils, accumulation, migration.

\section{INTRODUCTION}

Long-term and large-scale use of pesticides has led to the appearance of ecotops contaminated with high concentrations of these compounds. These sites pose a threat to the environment and human health, as they are a source of toxic substances from the soil in the trophic chains.

Inefficient warehouses and adjacent territories remain sources of environmental pollution by pesticides and their metabolites, including persistent organic pollutants. The extent of soil contamination around agrochemicals, the depth of migration and the amount of persistent pesticides presently found in the soil is unknown. Due to lateral and radial migration, water and air transfer, they can enter the water sources, poison agricultural products and accumulate in higher levels of trophic chains.

Numerous publications on the presence of residual amounts of isomers and metabolites of DDT and HCFCs in agricultural soils suggest that the problem associated with the use of these insecticides in the past in crop production is also relevant today. Around the places of storage formed areas of local pollution. The content of resistant xenobiotics in soils of such areas is tens, and sometimes hundreds of times higher than hygienic standards (Grosby 1982; Fedorov and Yablokov 1999; Furdychko et al. 2010; Furdychko 2012).

Recent studies have shown that DDT can migrate to deep soil horizons due to complex formation in soil solutions (Shea 1985; Moklyachuk et al. 2006; Furdychko 2012; Ivankiv and Vovk 2012; Smidova 2013). In previous papers (Ivankiv and Vovk 2012), we described the

Correrspondinq author: Stakh Vovk, Institute of Agriculture in the Carpathian region of NAAS, Grushevskoho 5, Obroshyno, 81115, Pustomytivs'kyi distr., Lviv region, Ukraine, e-mail: vovkstah@gmail.com 
severity of the problem of soil and vegetation contamination by organochlorine pesticides. Without solving these problems it is impossible to expect the formation of sustainable agroecosystems in the future. Therefore, research in the above aspect is relevant and of considerable scientific and practical interest.

Particularly dangerous for human health and the environment are organochlorine pesticides, namely isomers and metabolites of DDT, as well as HCFC isomers. DDT decomposes with the formation of almost exclusively hydrophobic compounds that are well soluble in fats (Mitra and Raghu 1989; Sandermann 1992; Fedorov and Yablokov 1999; Furdychko et al. 2010).

In order to prevent the spread of toxic substances from areas of local pollution to adjacent objects of the environment, it is important to conduct a permanent ecotoxicological assessment, which includes the study of possible ways of horizontal and vertical migration of xenobiotics, their receipt in trophic chains, the final link of which is a people.

\section{MATERIAL AND METODS}

The research was carried out on a dark grey-podzolized soil on the territory of the sanitary zone of the non-operating structure of agrochemicals. In order to study the content of organochlorine pesticides and their derivatives samples of soil from sanitary-protective zones of non-active compounds of pesticides in the village of Glinsko and village Vyazova of Zhovkivsky district of Lviv region were selected. The specified compositions of pesticides have not been used since 1990. The average samples of soil from a layer of 0-20 cm were selected by the method of a rhombic grid at a distance of 2, 5, 10 and 50 meters from the foundations of the warehouses according to the method described in the methodological recommendations (Furdychko et al. 2010). The analysis of soil samples was carried out at the Lviv Regional State Design and Technology Centre for the Protection of Soil Fertility and the Quality of the "Oblderzhrodyuchist" products.

The research was carried out in accordance with existing regulations and "Methodological guidelines for the determination of the micro-hardness of pesticides in food, feed and environment" (Klysenko 1992; Furdychko et al. 2010). The content of organochlorine pesticide residues was determined by the method of gas-liquid chromatography according to the procedure approved by the Ministry of Health on the gas chromatograph "Crystal-2000" (Klysenko 1992; Furdychko et al. 2010). The maximum concentration of DDT and HCCG in the soil is $100 \mu \mathrm{g} / \mathrm{kg}$. The obtained data was processed by statistical methods using the program Statistica-10 and the package of Microsoft Excel applications.

\section{RESULTS AND DISCUSSION}

Organic pesticides are found in all soil samples (Table 1). The content of the sum of isomers of HCCs exceeded the established maximum permissible concentrations by 1.3 times only in soil samples taken at a distance of $2 \mathrm{~m}$ in the western direction from the warehouse v. Glinsko In other points of selection, the content of $\mathrm{HCHG}$ in the soil varied 
within the range of $0.5-50.7 \mu \mathrm{g} / \mathrm{kg}$. In many cases, the concentrations of HCCs found are significantly higher than the background pollution of agricultural land with pesticide residues, which may indicate that it has been stored in these warehouses in the past.

Table 1. The range of fluctuation of the concentration of organochlorine pesticides in the soil layer is $0-20 \mathrm{~cm}$ depending on the sides of the horizon $\left[\mathrm{mcg} \cdot \mathrm{kg}^{-1}, \mathrm{M} \pm \mathrm{m}\right]$

\begin{tabular}{|c|c|c|c|c|}
\hline \multirow[b]{2}{*}{$\begin{array}{c}\text { Distance From } \\
\text { TheWarehouse } \\
\text { [m] }\end{array}$} & \multicolumn{2}{|c|}{ V. Glinsko } & \multicolumn{2}{|c|}{ V. Vyazova } \\
\hline & $\begin{array}{c}\Sigma 4.4 \text { 'DDT + } \\
4.4 \text { 'DDD + } \\
4.4^{\prime} \mathrm{DDE} \\
\end{array}$ & $\begin{array}{c}\Sigma \alpha-H C H C G+ \\
\gamma-H C H C G+ \\
\beta-H C H C G\end{array}$ & $\begin{array}{c}\sum 4.4 \text { 'DDT + } \\
4.4 \text { 'DDD + } \\
4.4^{\prime} \text { DDE }\end{array}$ & $\begin{array}{c}\Sigma \alpha-H C H C G+ \\
\gamma-H C H C G+ \\
\beta-H C H C G\end{array}$ \\
\hline 2 & $105.4-1735.7$ & $0.5-48.2$ & $6.0-16.9$ & $0.5-21.9$ \\
\hline 5 & $98.7-1523.2$ & $0.5-38.4$ & $0.1-119.4$ & * -76.3 \\
\hline 10 & $76.4-2435.4$ & ${ }^{*}-50.7$ & ${ }^{*}-100.7$ & ${ }^{*}-71.4$ \\
\hline 50 & $43-223.1$ & * & ${ }^{*}-8.6$ & * \\
\hline MAC & & & & \\
\hline
\end{tabular}

* In the table indicates that these figures have not been determined.

A significant pollution of the soil of the sanitary zone with the composition of poison chemicals has been established. The most contaminated were the western direction (more than 24 MPCs), where, at a distance of $45 \mathrm{~m}$ from the warehouse, there are agricultural land and eastern direction (more than 14 MPCs), where, according to the stored documentation, there was a technological zone for the preparation of working solutions of pesticides. In general, there is a tendency to gradually reduce the content of the detected toxicant as far as the composition is concerned.

The obtained results indicate the large-scale contamination of the DDT adjacent to the territory and the need to control the content of organochlorine pesticides in soils and plants. According to the existing indicators of chemical degradation of soils, depending on the content of DDT, the soil of the sanitary-protective zone of the composition of poison chemicals v.Glinsko are in satisfactory condition (at a distance of $50 \mathrm{~m}$ in the southern direction from the warehouse); pre-crisis state (southern direction at a distance of $10 \mathrm{~m}$ from the warehouse and the northern direction - at a distance of 5-50 m from the warehouse); crisis condition (up to $2 \mathrm{~m}$ in the northern direction and $50 \mathrm{~m}$ in the eastern direction from the warehouse) and disastrous condition (at a distance of 2-5 $\mathrm{m}$ in the southern direction, 2-10 $\mathrm{m}$ in the eastern direction and at all sampling points in the western direction from the warehouse).

Within the sanitary-protective zone of the composition of poison chemicals with the samples of soils found on the 5 and $10 \mathrm{~m}$ distance in the south direction found the number of DDT at the level of MAC. In all other cases, the total content of DDT did not exceed the established hygienic standards and was a background for agricultural land in Ukraine. In general, with the distances from the composition of the toxicant in the soil decreased. Such content of organochlorine pesticide residues in the soil of the sanitary zone of the composition of pesticides may indicate a short term or small amounts of storage of pesticides 
in the warehouse. The contents of the amount of isomers and metabolites of DDT in the southern direction at distances of 50 and $10 \mathrm{~m}$ are predominantly pre-crisis (pre-crisis), in other cases they are not degraded or weakly degraded (up to $0.5 \mathrm{MAC}$ ).

\section{RECAPITULATION}

When introducing into agricultural use of soils of sanitary zones of the warehouses of agrochemicals it is mandatory to carry out their preliminary examination for the pollution of organochlorine pesticides and their derivatives. When detecting these polyants above the permissible standards, such soils should be removed from use.

\section{REFERENCES}

Grosby D.G. 1982. Atmospheric reactions of pesticides. Pest. Chem., Human Welfare and The Environ. 3, 327-332. [in Ukrainian]

Fedorov L., Yablokov A. 1999. Pesticides - toxic impact on the biosphere and hit people. Moscov, Science, 461. [in Russian]

Furdychko O., Movchan M., Moklyachuk L. 2010. Methodological recommendations on phytotesting persistent pesticides contaminated soils. Kyiv, [b.w.], 21. [in Ukrainian]

Furdychko O. 2012. Scientific basis for sustainable development of agroecosystems Ukraine. Ecological safety of agroindustrial production. Part 1. Kyiv, DAI, 352. [in Ukrainian]

Ivankiv M., Vovk S. 2012. Features of the accumulation of organochlorine pesticides in soil in areas syllables of storage, in: Proceedings of the conference "Ways of ensuring environmental safety areas". Lugansk, [b.w.], 39-45. [in Ukrainian]

Klysenko M. 1992. Methods for determining microquantity pesticides products in the power supply feeds and stored in an environment of foreign: a reference. Moscov, Kolos, 11. [in Russian]

Mitra J., Raghu K. 1989. Effects of DDT on the growth of crop plants. Environ. Poll. 61, 157-170.

Moklyachuk L., Andrienko G., Horodyska I. 2006. Field research of sites polluted with pesticides. Meeting of COST Action. Sintra, Portugal, [b.w.], 16.

Sandermann H. 1992. Plant metabolism of xenobiotics. Trends Biochem. Sci. 17(2), 82-84.

Shea P.J. 1985. Detoxification of herbicide residues in soil. Weed Sci. 2, 33-41.

Smidova K. 2013. Bioavailability of persistent organic pollutants in soils with regard to soil properties and contamination aging. Brno, Czech Republic, 92. 